seen in rare specimens of Kimberella (Fig. 1e) are impressions left by sclerites or spicules like those of halkieriids and some molluscs, although no actual sclerites have yet been recovered. More material will be needed to test this hypothesis.

We cannot prove a molluscan affinity conclusively; some definitive molluscan synapomorphies, like the radula, cannot be seen, and others are open to other interpretations. However, no other extant metazoans resemble Kimberella as closely. Metamerism is consistent with a flatworm grade of organization, but the firm parts and complex anatomy of Kimberella tend to rule out a relationship to the Platyhelminthes. Kimberella somewhat resembles certain pelagic salps (phylum Urochordata), which have an oval shape, a tough thickened outer test, and serial muscle bands that could resemble the crenellations of Kimberella ${ }^{19}$. However, not only was Kimberella benthic, it lacks the atrial and branchial openings and the distinctive budding growth pattern of salps. The benthic habitat and absence of tentacles or obvious zooids rule out an affinity with siphonophores or chondrophorines. Kimberella superficially resembles ctenophores such as Beroë, but its resistant nature and lack of octamerous symmetry rule out a ctenophore affinity. Nor can we interpret Kimberella as a non-metazoan 'Vendobiontan'20, protist $^{21}$, or lichen ${ }^{22}$. It is always possible to stretch such hypotheses to cover almost any fossil imaginable, but we can find no definite features that would place Kimberella in any of these groups. Kimberella has nothing like the 'quilted pneu' morphology which has been used to argue against metazoan affinities for other Ediacaran fossils ${ }^{19}$, and its complex structural properties are not well explained by protist or lichen models.

We conclude that Kimberella is a bilaterian metazoan, more complex than a flatworm, more like a mollusc than like any other metazoan, and plausibly bearing molluscan synapomorphies such as a shell and a foot. This interpretation counters assertions that the Ediacara biota represents an extinct grade of non-metazoan life. It confirms hypotheses based on trace fossils that metazoan triploblastic lineages, including 'molluscan-grade bilaterians', began to diversify before the beginning of the Cambrian ${ }^{23}$. It also suggests a pre-Ediacaran origin of major metazoan clades.

Received 23 October 1996; accepted 27 May 1997.

1. Glaessner, M. F. \& Daily, B. The geology and Late Precambrian fauna of the Ediacara fossil reserve. Rec. S. Aust. Mus. 13, 369-401 (1959).

2. Glaessner, M. F. \& Wade, M. The Late Precambrian fossils from Ediacara, South Australia. Palaeontology 9, 599-628 (1966).

. Wade, M. Hydrozoa and Scyphozoa and other medusoids from the Precambrian Ediacara fauna, South Australia. Palaeontology 15, 197-225 (1972).

4. Glaessner, M. F. The Dawn of Animal Life (Cambridge University Press, Cambridge, 1984).

5. Jenkins, R. J. F. Interpreting the oldest fossil cnidarians. Palaeontograph. Am. 54, 95-104 (1984).

6. Jenkins, R. J. F. in Origin and Early Evolution of the Metazoa (eds Lipps, J. H. \& Signor, P. W.) 131-176 (Plenum, New York, 1992).

Gehling, J. G. The case for Ediacaran fossil roots to the metazoan tree. Mem. Geol. Sco. India 20, 181224 (1991).

8. Shanker, R. \& Mathur, V. K. Precambrian-Cambrian sequence in Krol belt and additional Ediacaran fossils. Geophytology 22, 27-39 (1992).

9. Fedonkin, M. A. in The Vendian System Vol. 1 (eds Sokolov, B. S. \& Iwanowski, A. B.) 3-70 (Springer, Heidelberg, 1990).

10. Fedonkin, M. A. Besskeletnaja fauna Venda i eë mesto v evoljutsii metazoa. Trudy Paleontologicheskogo Instituta 227, 1-174 (Nauka, Moscow, 1987).

11. Grazhdankin, D. V. \& Ivantsov, A. Yu. Reconstructions of biotopes of ancient Metazoa of the Late Vendian White Sea biota. Paleontol. J. 30, 674-678 (1996).

12. Wade, M. Preservation of soft-bodied animals in Precambrian sandstones at Ediacara, South Australia. Lethaia 1, 238-267 (1968).

13. McMenamin, M. A. S. \& McMenamin, D. L. S. The Emergence of Animals: the Cambrian Breakthrough (Columbia University Press, New York, 1989).

14. Smith, D. C. \& Douglas, A. E. The Biology of Symbiosis (Arnold, London, 1987).

15. Buss, L. W. \& Seilacher, A. The Phylum Vendobionta: a sister group of the Eumetazoa? Paleobiology 20 1-4 (1994)

16. Morton, J. E. in The Mollusca 11: Form and Function (eds Trueman, E. R. \& Clarke, M. R.) 253-286 (Academic, San Diego, 1989).

17. Conway Morris, S. \& Peel, J. S. Articulated halkieriids from the Lower Cambrian of North Greenland. Nature 345, 802-805 (1990).

18. Conway Morris, S. \& Peel, J. S. Articulated halkieriids from the Lower Cambrian of North Greenland and their role in early protostome evolution. Phil. Trans. R. Soc. Lond. B 347, 305-358 (1995)

19. Berrill, N. J. in The Tunicata: with an Account of the British Species. Figs 105, 106, 107 (Ray Society, London, 1950).

20. Seilacher, A. Vendobionta and Psammocorallia: lost constructions of Precambrian evolution. J. Geol. Soc. Lond. 149, 607-613 (1992).

21. Zhuravlev, A. Yu. Were Ediacaran Vendobionta multicellulars? N. Jb. Geol. Paläontol. 190, 299-314 (1993).
22. Retallack, G. J. Were the Ediacaran fossils lichens? Paleobiology 20, 523-544 (1994).

23. Valentine, J. W. Late Precambrian bilaterians: grades and clades. Proc. Natl Acad. Sci. USA 91, 675164757 (1994).

Acknowledgements. We thank the volunteers and colleagues who collected much of this material, in particular A. Yu. Ivantsov, D. V. Grazhdankin, J. Woland and A. G. Collins; Yu. I. Nikolaev, L. S. Zakharchenkova, the Paleontological Institute in Moscow, and the Arkhangel'skgeologiya office in Arkhangel'sk, for field logistical support; R. van Syoc (California Academy of Sciences) for access to specimens of extant invertebrates; D. R. Lindberg and J. G. Gehling for helpful comments; A. Mazin for photography and Y. A. Afanasiev for artwork.

Correspondence and requests for materials should be addressed to B.M.W. (e-mail: bmw@uclink2. berkeley.edu)

\section{A neuronal population code for sound localization}

\section{Douglas C. Fitzpatrick, Ranjan Batra, Terrence R. Stanford \& Shigeyuki Kuwada}

Department of Anatomy, University of Connecticut Health Center, Farmington, Connecticut 06030-3405, USA

The accuracy with which listeners can locate sounds is much greater than the spatial sensitivity of single neurons ${ }^{1-3}$. The broad spatial tuning of auditory neurons indicates that a code based on the responses of ensembles of neurons, a population code, must be used to determine the position of a sound in space. Here we show that the tuning of neurons to the most potent localization cue, the interaural time difference in low-frequency signals $(<\sim 2 \mathrm{kHz}$; refs 4,5 ), becomes sharper as the information ascends through the auditory system. We also show that this sharper tuning increases the efficiency of the population code, in the sense that fewer neurons are required to achieve a given acuity.

Sensitivity to interaural time differences (ITDs) first occurs in the main nuclei of the superior olivary complex (SOC). The information is then transmitted to the inferior colliculus, and from there to the auditory thalamus, which in turn projects to the auditory cortex. We examined ITD sensitivity at its point of creation (the SOC) and at two higher levels (inferior colliculus and auditory thalamus) through neural recordings in unanaesthetized rabbits.

Examples of the ITD tuning in the SOC and thalamus are shown in Fig. 1a. These 'composite' ITD curves represent the averaged responses to tones of different frequencies as a function of ITD 6 . In both nuclei, the curves are overlapping and broad in relation to the total range represented. Note, however, that the ITD tuning widths in the thalamus are much narrower than in the SOC.

The sharpening of ITD tuning as the information ascends the auditory system is also shown in Fig. 1b, c. The mean width of the composite curves showed a large decrease for the SOC to the inferior colliculus (730 to $430 \mu \mathrm{s}$ ), and a smaller decrease from there to the thalamus ( 430 to $350 \mu$ s) (Fig. 1b). The sharpening was not due to differences in the frequency content to which the samples of neurons in each structure responded, because it also occurred on a frequency-by-frequency basis (Fig. 1c). Much of the sharpening must therefore be due to neural processing. Possible mechanisms for the sharpening include inhibitory processes ${ }^{2,7}$ and convergence of temporally coincident activity ${ }^{8}$.

To determine how the sharpening of ITD tuning affects performance at each level, we used a model similar to that described in refs 9,10 . This model is similar to the 'position-variable' model of ITD sensitivity derived from behavioural data and responses from the auditory nerve ${ }^{11}$. Such models begin by aligning all the neurons according to their preferred sensitivity, in this case the best ITD, to form a 'neural axis'. To the extent that the spatial field is not mapped

* Present address: Department of Neurobiology and Anatomy, Bowman Gray Medical School, Winston Salem, North Carolina 27157-1010, USA 
uniformly, the representation in the neural axis is distorted. In each nucleus, the distribution of best ITDs was peaked and biased towards ipsilateral (negative) delays, corresponding to sounds in contralateral space (Fig. 2a). The distorted neural representation that results is shown for the thalamus in Fig. 2b (top). The thalamic neurons are arrayed according to the best ITD, and the neural axis divided into 100 arbitrary units. The distortion in the map is evident, in that the first 40 neural axis units span $733 \mu$ s of ITD, whereas the next 40 units span only $208 \mu$ s; the remaining 20 units span $1,153 \mu$ s.
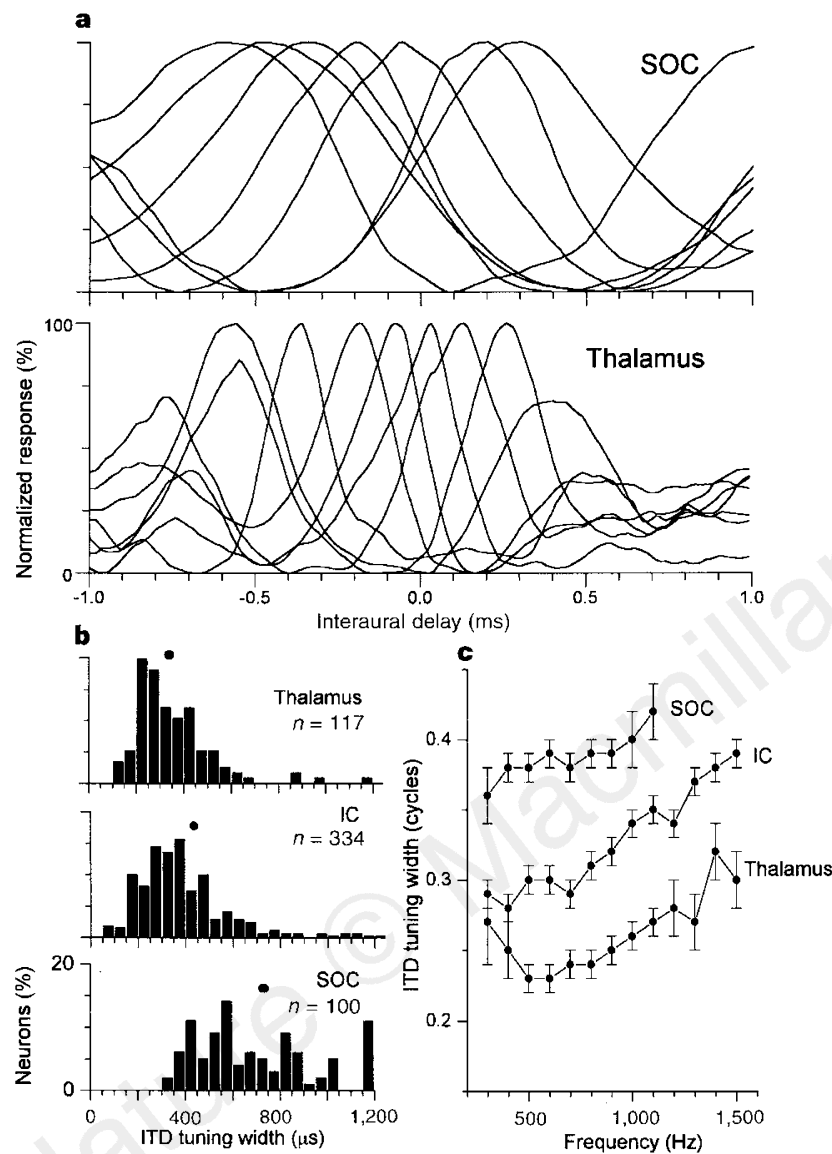

Figure 1 Sharpening of ITD tuning as the information ascends the auditory system. a, Examples of ITD tuning of neurons in the superior olivary complex (SOC) and auditory thalamus. Based on reconstructions from lesions made at the end of recording, the neurons in the SOC were primarily in the medial and lateral superior olives ${ }^{29}$, whereas the thalamic neurons were located primarily in the posterior group of the thalamus and ventral and medial nuclei of the medial geniculate body ${ }^{30}$. Each curve is the composite of responses to 'binaural-beat' stimuli (see Methods) of different frequencies that spanned the ITD-sensitive range for each neuron. The widths of the composite curves shown are near the median obtained for the SOC and auditory thalamus, respectively. The ITD tuning is much sharper in the thalamus than in the SOC. $\mathbf{b}$, Distribution of composite curve widths measured at half-maximal response. The neurons at each level had a wide range of ITD tuning widths, but the mean (circles) shifted to progressively lower values as the information ascended. c. The widths of ITD curves to individual frequencies, measured at half-maximal response. Sharpening occurred on a frequency-by-frequency basis. Bars are standard errors based on the number of neurons sensitive to each frequency.
The performance of neurons at each level was assessed by using signal detection theory ${ }^{12}$ to calculate the minimum detectable change in ITD that could be detected by different numbers of neurons. The response of each neuron to a range of target ITDs was obtained from their composite curves (Fig. 1a). In Fig. 2b (top), the responses of thalamic neurons $(n=117)$ to a target ITD of $-100 \mu \mathrm{s}$ (arrow) is represented by a series of vertical lines, one for each neuron, whose height is proportional to the maximal response of that neuron. By sampling from this distribution, we evaluated the ability of different numbers of neurons to discriminate changes in

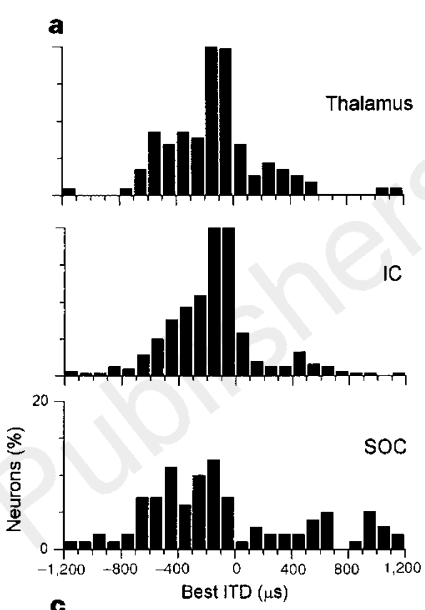

b
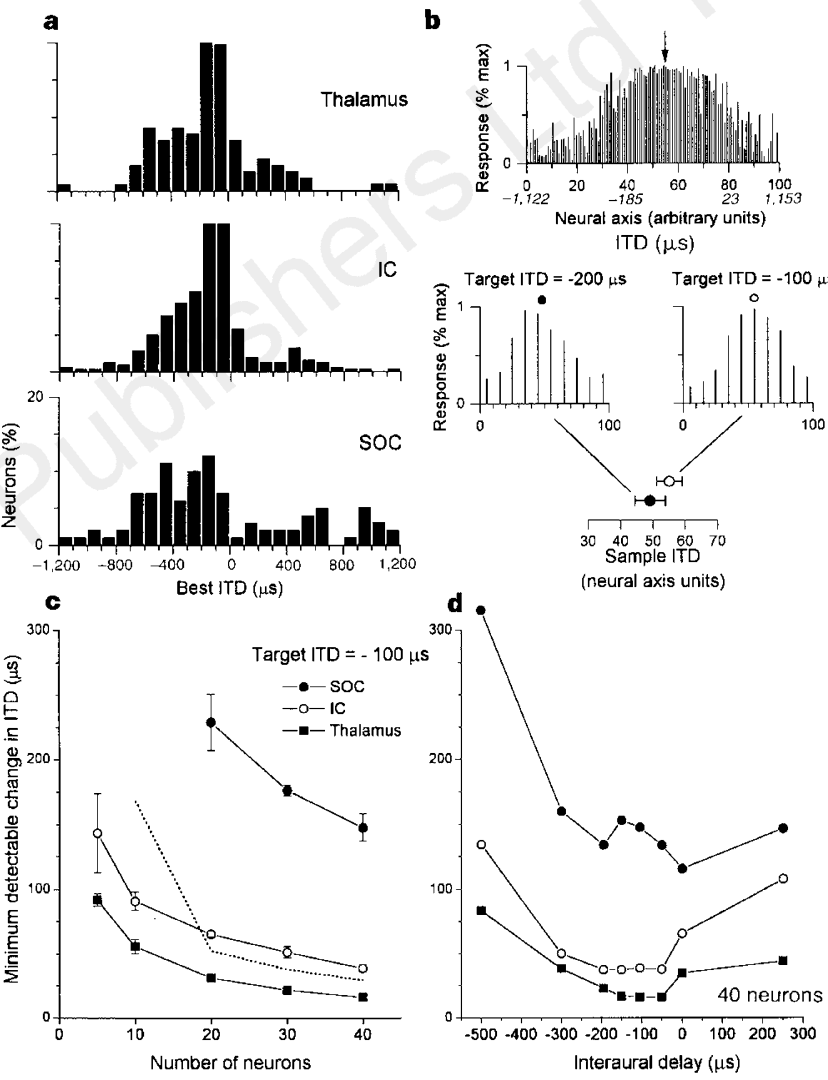

Figure 2 Construction and performance of a population model for ITD sensitivity. a, Distributions of best ITDs, or peaks of composite curves (Fig. 1a). These nonuniform distributions indicate that a portion of contralateral space is overrepresented. b, Implementation of the model. The example shown is from the thalamus. Top, normalized responses of the neurons (vertical lines), arrayed according to their best ITD, to a target ITD of $-100 \mu \mathrm{s}$ (arrow). Middle, the responses to two target ITDS for a sample of 10 neurons. Neurons were randomly drawn, with replacement, from blocks evenly spaced along the ITD axis. A sample ITD to each target (circles) was determined according to $P=\Sigma_{i}\left(\mathrm{~b} / \mathrm{TD}_{i}^{*} r_{i}\right) / \Sigma r_{i}$, where bITD; was the best ITD of the $i$ th neuron in neural ITD units, and $r_{i}$ was the normalized response obtained from the composite curve. Bottom, means and standard deviations of sample ITDs for 100 samples of 10 neurons. A minimal detectable change in ITD was defined ${ }^{12}$ as a $d^{\prime}$ of 1 (equivalent to about $75 \%$ correct responses), where $d^{\prime}=\left|\left(\left\langle P_{1}\right\rangle-\left\langle P_{2}\right\rangle\right)\right| /\left(S_{1}^{2}+S_{2}^{2}\right)^{1 / 2}$, with $\left\langle P_{1}\right\rangle$ and $\left\langle P_{2}\right\rangle$ equal to the mean sample ITD for each target and $s_{1}$ and $s_{2}$ the standard deviations. c, Minimum detectable change as a function of the number of neurons per sample. The points are the mean of 5 determinations of the minimum detactable ITD; the bars are the standard error. d, Minimum detectable change for 40 neurons to different target ITDs. At each level the acuity is highest in the regions of densest representation. The results are based on the results from one side only, because lesions in one hemisphere generally affect localization performance in contralateral space, as if responses from the two sides are not pooled. 
ITD. Our method of evaluation is shown in Fig. 2b: the left middle panel represents the responses of 10 neurons drawn at random from one of 10 equally spaced blocks on the neural ITD axis to a target ITD of $-200 \mu \mathrm{s}$ - the 'sample ITD' (circle) encoded by these neurons is given by the weighted average of the responses; the right middle panel shows the responses and sample ITD (circle) of the same neurons to a different target ITD $(-100 \mu \mathrm{s})$. By repeating this process 100 times using different samples of neurons, the means and standard deviations of the sample ITDs were determined (Fig. $2 \mathrm{~b}$, bottom). These were compared for each sample size to determine a minimum detectable change in ITD (Fig. 2, legend). The aim of the model was to assess the efficiency of the population code for ITD representation at each level in terms of the number of neurons required to detect a given change in a stimulus ITD.

The results indicate that the effect of sharpening is to increase the efficiency of the population code. In Fig. 2c, we show the acuity achieved for different numbers of neurons at each level. The bars represent the standard error for five determinations of the minimum detectable ITD. For a target ITD of $-100 \mu \mathrm{s}$, the acuity for all sample sizes was greatest in the thalamus, worst in the SOC, and intermediate in the inferior colliculus. For example, using 40 neurons a change of $147 \mu \mathrm{s}$ could be detected in the SOC, $39 \mu \mathrm{s}$ in the inferior colliculus, and $16 \mu \mathrm{s}$ in the thalamus. Viewed from another perspective, to achieve a given acuity, fewer and fewer neurons were needed as the information ascended.

Further sharpening, however, does not necessarily result in a further increase in efficiency. When the thalamic neurons were artificially sharpened by an additional $50 \%$, the performance decreased (Fig. 2c, dotted line). This effect is not unexpected, because in a noisy channel, sharper tuning beyond some optimal level will result in greater resolution of multiple stimuli but at the cost of increasing numbers of neurons to maintain the same degree of accuracy for all points in space ${ }^{13,14}$. The decline in performance with artificial sharpening therefore suggests that the tuning of thalamic neurons is nearly optimal for maximum efficiency for the accurate representation of ITDs using a minimum of neurons. However, because the composite ITD curves are often complex (that is, they have sidebands; Fig. 1a), it was not clear whether the effect of that artificial sharpening was due to a decrease in peak width or to bringing the sidebands closer to the main peak. We therefore repeated the simulations using gaussian curves with ITD tuning and noise (d.c.) levels comparable to those of the recorded neurons, but without sidebands, and achieved a similar result. The auditory system therefore sharpens overly broad tuning from the SOC until it is appropriate for a maximally efficient population code. However, the final code still consists of elements that can be described as broadly tuned, in that they occupy a significant fraction of the total sensory field (on average $350 \mu$ s in a physiological range of $\sim 600 \mu \mathrm{s}$, based on the rabbit's head width ${ }^{15}$ ).

An additional feature shown by the model is that performance at
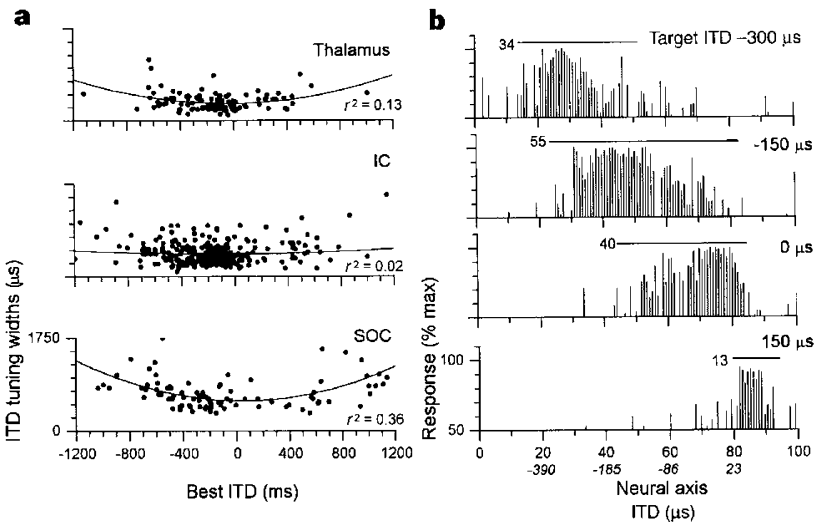

each level was best over a range of ITDs in the centre of the distribution, and was markedly worse for more peripheral ITDs (Fig. 2d). In the region of ITDs near the edge of the physiological range ( $-300 \mu$ s ITD), the performance was about half as good as in the centre. This feature has a behavioural correlate in humans, where sensitivity to changes in ITD declines by about a factor of two between the centre and the periphery ${ }^{16}$.

The increased performance at some ITDs at each level differs from a similar change seen in azimuthal visual spatial acuity. In the visual system, the sizes of receptive fields scale almost linearly with neural density. This relationship yields 'point images', defined as the amount of neural tissue representing any single point in the sensory field, which are nearly constant from centre to periphery. This organization is seen in visual cortex, where the definition is similar to that of the 'hypercolumn' ${ }^{17}$, and in the superior colliculus ${ }^{18}$. Higher acuity in the foveal representations arises because a smaller distance in visual space is required to move to a neighbouring module with a non-overlapping receptive field. By contrast, in the ITD system, neurons in the densest part of the distribution of best ITD are not markedly sharper than at more peripheral ITDs (Fig. $3 a$ ). This yields point images that are larger in the centre than at the periphery (Fig. 3b). This is equivalent to saying that receptive fields in the ITD system are not represented by equal-sized modules.

A consequence of point images that occupy a large fraction of available neural tissue is that such an organization is inherently poor at resolving multiple, simultaneous stimuli ${ }^{13,19}$. Other systems based on similar broadly tuned neurons include the monkey motor cortex $^{9,10}$, the saccade system in the superior colliculus ${ }^{20,21}$, and cricket cercal cells that measure wind direction ${ }^{22}$. In such cases population codes based on broadly tuned elements make considerable sense, because there can be only one arm movement, saccade or wind direction at a time. In contrast, the auditory system is faced at once with multiple, spatially segregated sources. This raises the question of how the locations of sources can be resolved neurally.

It could be that multiple sources are resolved along a dimension orthogonal to ITD, such as frequency. However, the average frequency tuning width (measured at half maximal response level) for thalamic neurons is $850 \mathrm{~Hz}$, compared to the total frequency range for ITD sensitivity of $\sim 1,800 \mathrm{~Hz}(\sim 200 \mathrm{~Hz}$ to $2 \mathrm{kHz})$. In fact, the change in frequency tuning as the information ascends is opposite to that of ITD tuning, in that it is narrowest in the SOC (average width, $560 \mathrm{~Hz})$ and wider in the inferior colliculus $(862 \mathrm{~Hz})$ and thalamus. Thus neurons at higher levels of the ITD representation are broadly tuned to frequency as well as to ITDs, further indicating that the system is optimized to measure the ITD of one, or at most a few, sources at a time.

Human listeners exhibit a decline in behavioural performance in the presence of multiple stimuli with different ITDs. The early studies that showed very high acuity to ITD $(<20 \mu \mathrm{s})$ used sequential rather than simultaneous stimuli ${ }^{1}$. Direct comparisons

Figure 3 The point image representation of ITDs. a, Distribution of the widths of composite ITD curves, measured at half-maximal response, as a function of best ITD. There was little, if any, tendency for neurons in the region of greatest representation to have particularly sharp tuning, especially above the level of the SOC. b. Point images for different ITDs in the auditory thalamus. The point image (the portion of the neural axis activated by a particular ITD) can be appreciated graphically here as the extent of activation of neurons (vertical lines) above a threshold level (50\% of maximal) to different target ITDs. The horizontal lines in each panel represent the calculated point image size $(P I)$ in neural ITD units, where $\mathrm{PI}=\left(R F_{m}\right)(M F)$, and $R F_{m}$ is the mean $50 \%$ tuning width for a given target ITD (in $\mu s$ ), and MF is the magnification factor (in neural ITD units per $\mu$ s of physical ITD) using a bin width of $100 \mu$ s for calculating $\mathrm{RF}_{m}$ and MF). Because the ITD tuning width does not decline with increased density of representation along the neural axis (a), the point images are larger in the centre of the distribution than in the periphery. 
show a decline in acuity in the presence of multiple source ${ }^{23}$, as do earphone studies with stimuli containing 'interfering' ITDs ${ }^{24-26}$. Our results suggest that the broadly tuned nature of the population code is the neural basis for this fundamental limitation. We suggest that to the extent we are aware of the locations of numerous, simultaneous sources, this 'auditory image' must be constructed on the basis of sequential determinations from different sources at different times.

\section{Methods}

Animals $(n=31)$ were surgically prepared under ketamine/xylazine anaesthesia by attaching a bar to the skull with screws and dental cement. In a second surgery, a small hole was drilled in the skull overlying the cortex and filled with removable elastomer. Recordings were made without anaesthetic. The animals were restrained by securing the body in a close-fitting bag and clamping the head bar. The elastomer was removed, local anaesthetic was applied to the dura, and the electrode was directed towards an auditory centre. Daily recordings lasting $\sim 2$ hours were made over a period of up to several months. Usually only a single nucleus was studied. Recordings consisted of single neurons or clusters of a few neurons. Responses were obtained to 'binaural-beat' stimuli, which were pure tones ( 3.1 to $5.1 \mathrm{~s}$ long and repeated 2-4 times at a constant sound pressure level, usually near $70 \mathrm{~dB}$ ) to each ear that differed in frequency by $1 \mathrm{~Hz}$. This frequency difference created a cyclically varying ITD with a period of $1 \mathrm{~s}$. Period histograms of the responses were created based on the $1-\mathrm{Hz}$ binaural beat frequency; these yield the response as a function of interaural time difference. In our unanaesthetized preparation there was little if any difference in ITD tuning widths to static or dynamic (binaural beat) stimuli. Curves (Fig. 1a) were smoothed by counting spikes in 10 bins per cycle of the stimulating frequency. For all calculations used in later figures, 25 bins per cycle were used. The initial $100 \mathrm{~ms}$ was omitted to avoid onset effects. A full description of recording and stimulus conditions is provided elsewhere ${ }^{27,28}$

Received 18 February; accepted 4 June 1997.

1. Mills, A. W. On the minimum audible angle. I. Acoust. Soc. Am. 65, 991-1000 (1958).

2. Kuwada, S., Batra, R. \& Fitzpatrick, D. C. in Binaural and Spatial Hearing in Real and Virtual Environments (eds Gilkey, R. H. \& Anderson, T. R.) 399-426 (Erlbaum, Mahwah, NJ, 1997)

3. Brugge, J. F., Reale, R. A. \& Hind, J. E. in Binaural and Spatial Hearing in Real and Virtual Environments (eds Gilkey, R. H. \& Anderson, T. R.) 447-474 (Erlbaum, Mahwah, NJ, 1997).

4. Blauert, J. Spatial Hearing: The Psychophysics of Human Sound Localization (MIT Press, Cambridge, MA, 1982)

Wightman, F. L. \& Kistler, D. J. The dominant role of low frequency interaural time differences in sound localization. J. Acoust. Soc. Am. 91, 1648-1661 (1992).

6. Yin, T. C. T. \& Kuwada, S. Binaural interaction in low-frequency neurons in inferior colliculus of the cat. III. Effects of changing frequency. J. Neurophysiol. 50, 1020-1042 (1983).

Li, L. \& Kelly, J. B. Inhibitory influence of the dorsal nucleus of the lateral lemniscus on binaural responses in the rat's inferior colliculus. J. Neurosci. 12, 4530-4539 (1992).

8. Stern, R. M. \& Trahiotis, C. in Auditory Physiology and Perception (eds Cazals, Y., Horner, K. \& Demany) 547-554 (Pergamon, Oxford, 1992).

9. Georgopoulos, A. P., Schwartz, A. B. \& Kettner, R. E. Neuronal population coding of movement direction. Science 233, 1416-1419 (1986)

10. Georgopoulos, A. P., Kettner, R. E. \& Schwartz, A. B. Primate motor cortex and free arm movements to visual targets in three-dimensional space. II. Coding of the direction of movement by a neuronal population. J. Neurosci. 8, 2928-2937 (1988).

11. Stern, R. M. \& Colburn, H. S. Theory of binaural interaction based on auditory-nerve data IV. A model for subjective lateral position. J. Acoust. Soc. Am. 64, 127-140 (1978).

12. Green, D. M. \& Swets, J. A. in Signal Detection Theory and Psychophysics 1-455 (Wiley, New York, 1966).

13. Hinton, G. E., McClelland, J. L. \& Rummelhart, D. E. in Parallel Distributed Processing Vol. I (eds Rummelhart, D. E. \& McClelland, J. L.) 77-109 (MIT Press, Cambridge, MA, 1986)

14. Salinas, E. \& Abbot, L. F. Vector reconstruction from firing rates. J. Comp. Neurosci. 1, 89-97 (1994)

15. Heffner, H. \& Masterton, B. Hearing in Glires: domestic rabbit, cotton rat, feral house mouse, and kangaroo rat. J. Acoust. Soc. Am. 68, 1584-1599 (1980).

16. Hafter, E. R. \& DeMaio, J. Difference thresholds for interaural delay. J. Acoust. Soc. Am. 57, 181-187 (1975).

17. Hubel, D. H. \& Wiesel, T. N. Receptive fields. Binocular interactions and functional architecture in the cat's visual cortex. J. Physiol. (Lond.) 160, 106-154 (1962)

18. Capuano, U. \& Mcllwain, J. T. Reciprocity of receptive field images and point images in the superio colliculus of the cat. J. Comp. Neurol. 196, 13-23 (1981).

19. Rummelhart, D. E., Smolensky, P., Hinton, G. E. \& McClelland, J. L. in Parallel Distributed Processin Vol. II (eds McClelland, J. L. \& Rummelhart, D. E.) 77-109 (MIT Press, Cambridge, MA, 1986).

20. Van Gisbergen, J. A. M., Van Opstal, A. J. \& Tax, A. A. Collicular ensemble coding of saccades based on vector summation. Neuroscience 21, 541-555 (1987).

21. Lee, C., Rohrer, W. H. \& Sparks, D. L. Population coding of saccadic eye movements by neurons in the superior colliculus. Nature 332, 357-360 (1988).

22. Theunissan, F. \& Miller, J. P. Representation of sensory information in the cricket cercal sensory systems. II, Information theoretic calculation of system accuracy and optimal tuning curve widths of four primary interneurons. J. Neurophysiol. 66, 1690-1703 (1991).

23. Perrott, D. R. Concurrent minimum audible angle: a re-examination of the concept of auditory spatial acuity. J. Acoust. Soc. Am. 75, 1201-1206 (1984).

24. Trahiotis, C. \& Bernstein, C. R. Detectability of interaural delays over select spectral regions: Effects of flanking noise. J. Acoust. Soc. Am. 87, 810-913 (1990).
25. Dye, R. H. The combination of interaural information across frequencies: Lateralization of the basis of interaural delay. J. Acoust. Soc. Am. 88, 2159-2170 (1990).

26. Heller, L. M. \& Trahiotis, C. Extents of laterality and binaural interference effects. J. Acoust. Soc. Am. 99, 3632-3637 (1996)

27. Kuwada, S., Stanford, T. R. \& Batra, R. Interaural phase sensitive units in the inferior colliculus of the unanesthetized rabbit. Effects of changing frequency. J. Neurophysiol. 57, 1338-1360 (1987).

28. Batra, R., Kuwada, S. \& Stanford, T. R. Temporal coding of envelopes and their interaural delays in the inferior colliculus of the unanesthetized rabbit. J. Neurophysiol. 61, 257-268 (1989).

29. Batra, R., Kuwada, S. \& Fitzpatrick, D. C. Sensitivity to interaural temporal disparities of low and high frequency neurons in the superior olivary complex. I. Heterogeneity of responses. J. Neurophysiol. (in the press)

30. Stanford, T. R., Kuwada, S. \& Batra, R. A comparison of the interaural time sensitivity of neurons in the inferior colliculus and thalamus of the unanesthetized rabbit. J. Neurosci. 12, 3200-3216 (1992).

Acknowledgements. We thank C. Trahiotis, L. Bernstein and L. Abbott for discussion, L. M. Seman for Acknowledgements. We thank C. Trahiotis, L. Bernstein and L. Abbott for discussion, L. M. Seman for grant from the Center for Deafness and Communicative Disorders, NIH, USA.

Correspondence and requests for materials should be addressed to D.C.F. (e-mail: dcf@neuron.uchc.edu).

\section{Loose-patch recordings of single quanta at individual hippocampal synapses}

\section{Lia Forti, Mario Bossi, Andrea Bergamaschi, Antonello Villa \& Antonio Malgaroli}

Department of Biological and Technological Research, DIBIT,

Scientific Institute San Raffaele, and Cellular and Molecular Pharmacology

Center, CNR, Department of Pharmacology, University of Milano,

Via Olgettina 58, 20123 Milano, Italy

Synapses in the central nervous system are typically studied by recording electrical responses from the cell body of the postsynaptic cell. Because neurons are normally connected by multiple synaptic contacts, these postsynaptic responses reflect the combined activity of many thousands synapses, and it remains unclear to what extent the properties of individual synapses can be deduced from the population response $\mathrm{e}^{1-5}$. We have therefore developed a method for recording the activity of individual hippocampal synapses. By capturing an isolated presynaptic bouton inside a loose-patch pipette and recording from the associated patch of postsynaptic membrane, we were able to detect miniature excitatory postsynaptic currents ('minis') arising from spontaneous vesicle exocytosis at a single synaptic site, and to compare these with minis recorded simultaneously from the cell body. The average peak conductance at a single synapse was about $900 \mathrm{pS}$, corresponding roughly to the opening of 90 AMPAtype glutamate-receptor channels. The variability in this conductance was about $30 \%$, matching the value reported for the neuromuscular junction ${ }^{6}$. Given that our synapses displayed single postsynaptic densities (PSDs), this variability is larger than would be predicted from the random opening of receptor channels, suggesting that they are not saturated by the content of a single vesicle. Therefore the response to a quantum of neurotransmitter at these synapses is not limited by the number of available postsynaptic receptors.

Individual CA3-CA1 hippocampal boutons, visualized with the fluorescent dye FM1-43 (refs 7, 8), were enclosed inside patch pipettes and loose-seals ${ }^{9}$ were gently formed with the dendritic membrane underneath (Fig. 1a, b). In this configuration, quantal signals from synapses positioned outside the pipette are not visible above background noise (see Methods). Thus this approach provides a simple way of looking at currents from single synapses in isolation. For synaptic loose-seal recordings, we selected isolated chains of fluorescent boutons, belonging to putative single axons, above large proximal dendrites $(\sim 0-70 \mu \mathrm{m}$ from the end of the soma) (Fig. 1a). The morphology of these contacts was analysed by serial electron microscopy (EM) of proximal dendrites. At these 